\title{
EDUCAÇÃO FÍSICA, PIBID E FORMAÇÃO DOCENTE: PROFESSORA OU ESTUDANTE?
}

\author{
PHYSICAL EDUCATION, PIBID AND TEACHER \\ EDUCATION: TEACHER OR STUDENT?
}

\section{EDUCACIÓN FÍSICA, PIBID Y FORMACIÓN DOCENTE: ¿DOCENTE O ESTUDIANTE?}

\author{
Beatriz Pereira \\ Universidade Federal do Rio de Janeiro \\ Renato Sarti \\ Universidade Federal do Rio de Janeiro
}

\section{RESUMO}

O contexto desencadeador do estudo foi o Programa Institucional de Bolsas de Iniciação à Docência (PIBID), dentro do curso de Licenciatura de Educação Física da Universidade Federal do Rio de Janeiro (UFRJ). A partir da modalidade de abordagem qualitativa História de Vida, busco compreender de que forma a minha participação no PIBID possibilitou aproximações com aspectos alinhados a uma perspectiva contra hegemônica de formação de professores para além da racionalidade técnica e prática. A partir dos meus escritos no Diário de Campo e da minha trajetória na educação básica, investigo aproximações aos conceitos freireanos e às concepções bancária e libertadora da educação. Desse modo, a pesquisa me permitiu perceber que o PIBID oportunizou aproximações com aspectos relacionados ao modelo de formação da racionalidade crítica.

Palavras-chave: PIBID, formação de professores, Educação Física escolar, Paulo Freire.

\footnotetext{
ABSTRACT

The insert context of the study was the Institutional Program for Teaching Initiation Scholarships (PIBID) inside the Physical Education Graduation course at the Federal University of Rio de Janeiro (UFRJ). So, based on the qualitative approach to Life History, I pretend to understand how my participation in PIBID allowed approximations with aspects aligned with a counter hegemonic
} 
perspective of teacher education beyond technical and practical rationality. Based on my writings in my Field Diary and my trajectory in basic education, I investigate approaches to Freirean concepts and to the banking and liberating conceptions of education. In this way, the research allowed me to realize that PIBID provided opportunities for approximations with aspects related to the model of formation of critical rationality.

Key words: PIBID, teacher education, Physical scholar Education, Paulo Freire.

\section{RESUMEN}

El contexto desencadenante del estudio fue el Programa Institucional de Becas de Iniciación Docente (PIBID), dentro de la Licenciatura en Educación Física de la Universidad Federal de Río de Janeiro (UFRJ). Desde el enfoque cualitativo de la Historia de Vida, busco comprender cómo mi participación en PIBID posibilitó enfoques con aspectos alineados con una perspectiva contrahegemónica de la formación docente más allá de la racionalidad técnica y práctica. Desde mis escritos en el Diário de Campo y mi trayectoria en la educación básica, investigo acercamientos a los conceptos de Freire ya las concepciones bancarias y liberadoras de la educación. Así, la investigación me permitió darme cuenta de que el PIBID brindaba oportunidades para aproximaciones con aspectos relacionados con el modelo de formación de la racionalidad crítica.

PALABRAS CLAVES: PIBID; formación de profesores; Educación Física escolar; Paulo Freire.

\section{Palavras Iniciais}

Este estudo foi construído por mim, uma pesquisadora, estudante, professora em formação, prima, madrinha, amiga, filha, angoleira, ex-judoca, entre muitas outras coisas. O trabalho contou ainda com a coautoria de um pesquisador, doutorando, trabalhador da Educação Brasileira, primo, irmão, pai, amigo, filho, companheiro, apaixonado pela cor amarela e por futebol, entre muitas outras coisas.

Destaco esta apresentação para que quem estiver lendo saiba que este trabalho é atravessado por múltiplos afetos e pessoas que talvez nem o lerão, já que “[...] as emoções estão na origem de cada ato - seja uma carícia no ser amado ou a prática de pesquisa científica [...]” (BAPTISTA, 2001, p. 7). Por isso não consigo acreditar no distanciamento entre a pessoa que pesquisa e o objeto a ser pesquisado, visto que considero a existência de uma relação de afeto a partir da construção do objeto de pesquisa.

Ao escolher a minha formação enquanto professora de Educação Física como 
objeto de estudo, considero fundamental a minha presença no discurso do texto e opto, portanto, pela redação em primeira pessoa. Assim, compreendo que a partir dessa escolha afirmo um posicionamento contra hegemônico em relação à redação da escrita científica, visto que em sua maioria são escritos em terceira pessoa, evitando o uso da primeira e segunda pessoa.

Desse modo, apoiada na modalidade de abordagem qualitativa História de Vida (SPINDOLA E SANTOS, 2003), busco compreender como a minha participação no Programa Institucional de Bolsas de Iniciação à Docência (PIBID) possibilitou aproximações com aspectos alinhados a uma perspectiva contra hegemônica de formação de professores, em confronto direto com as estruturas fortificadas pela racionalidade técnica e prática. À medida que percebi as múltiplas disputas de modelo de formação durante a minha presença no PIBID, o processo de compreensão da minha formação tornou-se imprescindível.

Inicio minha narrativa na seção intitulada "História de vida e as minhas escolhas metodológicas", demarcando os caminhos percorridos na construção da presente pesquisa. Em seguida, em "Trajetória formativa: entre a Educação Bancária e a Educação Libertadora”, proponho um diálogo entre a minha história na educação básica até a atuação no PIBID, articulando-as com a concepção bancária e libertadora da educação, segundo Freire (2019). Além disso, busco contextualizar o cenário que desencadeou o presente estudo, apresentando o desdobramento do "Subprojeto Educação Física UFRJ: Cultura Corporal, Autonomia e Conhecimento", atuando no âmbito do curso de Licenciatura em Educação Física da Universidade Federal do Rio de Janeiro (UFRJ), tendo iniciado suas ações em Agosto de 2018 e encerrado em Dezembro de 2019.

Já em "Notas de uma formação contra hegemônica" pretendo compreender de que forma os modelos de formação hegemônicos e contra hegemônicos, discutidos por Diniz-Pereira (2011), se aproximam da minha vivência nas disciplinas da graduação e dos meus escritos do Diário de Campo, mobilizando os conceitos de práxis, quefazer e dialogicidade. O Diário de Campo foi um pequeno caderno entregue no início do Subprojeto, ocupando a função de permitir que nós, licenciandas e licenciandos, registrássemos nossas reflexões através da escrita. 


\section{História de vida e as minhas escolhas metodológicas}

No conjunto das diversas modalidades de abordagem qualitativa, trilho na direção da História de Vida, por acolher a ideia de que, por meio da narração sobre as vivências da minha vida, permito-me refletir e traçar novos horizontes para minha formação pessoal e profissional. Isto tem sido ressaltado por Spindola e Santos (2003), visto que "Uma narrativa tem uma função descritiva e avaliadora pois, quando relatamos um fato, na verdade, estamos tendo oportunidade de refletir sobre aquele momento". (SPINDOLA E SANTOS, 2003, p. 121)

Ao me entender enquanto ser inconclusa e histórica, esse método me proporciona o ato de resgatar a minha memória, que por sua vez "faz emergir a necessidade de se construir um olhar retrospectivo e prospectivo no tempo e sobre o tempo reconstituído como possibilidade de investigação e de formação de professores" (DE SOUZA, 2007, p. 63-64). Isto remete à utilização da memória contextualizada em um tempo específico que permite a investigação da formação profissional do professor.

\section{Trajetória formativa: entre a Educação Bancária e a Educação libertadora}

As primeiras práticas pedagógicas no Brasil começaram desde o século XVI. Preocupados com a apreensão da leitura e escrita pelos povos originários, os jesuítas atracaram nestas terras com a transparente finalidade de propagar os seus ensinamentos religiosos. No entanto, a minha trajetória se iniciou no século XXI, com dois anos de idade e em uma creche particular no bairro de Olaria, localizado na Zona Norte da cidade do Rio de Janeiro. Estudei durante toda a educação básica na rede privada de ensino, o que me coloca, enquanto mulher preta, na posição de 
classe média. O meu entendimento sobre classe média neste trabalho se aproxima da condição de "um grupo subalternizado, instável, incipiente e que encontra muitas dificuldades em manter-se na posição de classe" (FIGUEIREDO, 2004, p. 203). Desse modo, por mais que eu tenha frequentado espaços onde a quantidade de pessoas brancas era superior do que a de pessoas pretas, não usufrui de saldos tão positivos.

Estudar em escolas particulares não me protegia dos materiais didáticos e aulas que mencionavam, exclusivamente, pessoas pretas no período do Brasil escravista, ao contrário, me permitiu que durante todo o processo de escolarização na educação básica naturalizasse seu aparecimento somente nessas circunstâncias. Além da invisibilidade das lutas, vitórias e produções dos meuśminhas ancestrais, refletindo até no modo em que penteava meu cabelo sempre preso, para que ninguém reparasse em sua textura crespa.

Percebo que esses comportamentos se aproximam do que Freire (2019) descreve como "comportamento prescrito", relacionando ao comportamento dos oprimidos, a partir da compreensão de que "toda prescrição é a imposição da opção de uma consciência a outra" (FREIRE, 2019, p. 46). Em suma, ao instalarem suas prescrições na consciência dos oprimidos, os opressores nos tornam alienados e temerosos por nossa liberdade.

Essas experiências evidenciadas aqui como "o que nos passa, o que nos acontece, o que nos toca" (BONDÍA, 2002, p. 21), se encontram atreladas a minha construção pessoal. Em sua reflexão, Jorge Larrosa Bondía destaca que a experiência se torna impossibilitada pela informação, e consequentemente, pela opinião. Isso se coloca explicito quando as grandes organizações caracterizam a sociedade que vivemos como "sociedade do conhecimento", conhecimento este caracterizado pela informação.

A respeito do excesso de informação, resgato minha vivência no terceiro ano do ensino médio de uma instituição privada, cuja finalidade do ensino era aprovação em vestibulares. Além da pressão pessoal e familiar sobre o Exame Nacional de Ensino Médio (ENEM), havia pressão dentro da instituição. Lembro-me que frequentemente os/as professores/as mencionavam sobre a importância da nossa 
aprovação no ENEM e, nos dias que não eram eles/as, era a gestão da instituição. Essa pressão aconteceu de diversas formas, seja oralmente ou por competição dentro do ambiente escolar. Praticamente em todos os finais de semana aconteciam os simulados, alguns nos moldes do ENEM e outros do Exame de Qualificação (EQ) da UERJ. O resultado das provas que representavam o ENEM servia para um ranking exposto no mural da escola, cuja finalidade era alocar os estudantes conforme seu rendimento.

Outra questão que tocou bastante em relação à competitividade e exposição foi a minha primeira experiência no EQ. A coordenação da escola sugeria que ficássemos depois da aula estudando, assim eu fazia. As aulas terminavam por volta de $13 \mathrm{~h}$, eu almoçava e estudava até $18 \mathrm{~h}$ dentro da própria instituição. Desse maneira, estudei até o primeiro EQ e quando saiu o resultado, havia alcançado a pontuação E, que me desqualificava do processo seletivo.

O vestibular ocorreu num domingo e na semana seguinte quando chego até a escola, me deparo com a listagem da classificação de todos e todas as estudantes expostas no mural principal prédio. Lembro-me como se fosse hoje a sensação de ter seu "fracasso" exibido para a escola toda ver. Nesse dia, me surpreendi comigo mesma, pois era tímida e pouco me impunha em situações de desconforto, mas naquele dia fui até a coordenação solicitar que aquilo fosse retirado e o fizeram.

Além disso, concordo com Bondía (2002) ao mencionar também que a falta de tempo torna a experiência cada vez mais rara. Observo essa questão quando retomo minha rotina na época da escola e uma parte da minha trajetória na universidade. Quando iniciei o $9^{\circ}$ ano, minha mãe e meu pai me matricularam em um curso preparatório para vestibulares de instituições técnicas. No entanto, em setembro iniciei minha jornada como atleta no judô representando um grande clube da cidade do Rio de Janeiro e, além dessas atividades, também cursava inglês. Dessa maneira, penso que as minhas possibilidades de vivenciar experiências se reduziram bastante.

Após terminar a educação básica e obter a nota do ENEM, inicio o processo do Sistema de Seleção Unificada (SISU), onde precisava escolher a profissão que almejava seguir depois de uma jornada intensa de memorização de informações. 
Destaco ainda, sobre o ingresso na universidade, que o Censo da Educação Superior de 2017, ano em que ingressei na UFRJ, mostra que apenas 19,7\% da população de 18 a 24 anos compartilhavam dessa mesma oportunidade, refletindo a estrutura de poder de que o ingresso na universidade ainda é um privilégio de poucos (INEP, 2018).

Ao narrar minha trajetória formativa, vejo que as experiências me possibilitaram assumir a presença da concepção bancária da educação como instrumento de opressão durante todo o processo. O referido processo guardava para os/as professores/as o protagonismo, me oferecendo o tradicional papel de mera figurante. Em suma, pude perceber que o "caráter especial e marcante - o de serem relações fundamentalmente narradoras, dissertoras" (FREIRE, 2019, p. 79) da relação educador-educando na escola, se materializou ao longo da narrativa de minha rotina escolar.

Essas experiências me impossibilitaram a vivência de outras, como aquelas pautadas na concepção problematizadora e libertadora da educação, que "afirma a dialogicidade e se faz dialógica" (FREIRE, 2019, p.95), permitindo a consciência enquanto ser inconclusa se fazendo cada vez mais humana ao reconhecer a vocação das pessoas de serem mais (FREIRE, 2019).

Ao adentrar na universidade, me deparo com pessoas de diversos lugares do Rio de Janeiro e até mesmo de fora da cidade. Chego ao final do meu primeiro ano no Ensino Superior e encontro um professor apaixonado pela educação brasileira, pela cor amarela e por futebol. Dentre as muitas conversas que nos aconteceram no término das aulas, uma delas tratou-se da divulgação do processo seletivo do PIBID. Dessa forma, no dia 26 de Junho de 2018, eu e aproximadamente 100 licenciandos recebemos um e-mail para o processo seletivo de bolsas de iniciação à docência. Foi a partir deste simples correio eletrônico que se iniciou a minha trajetória e de 29 licenciandos em algo que, até o momento era só uma sigla, o PIBID.

Preciso registrar que o dia 06 de Julho de 2018 também me tocou, data em que recebi o e-mail de que havia sido classificada no processo seletivo do PIBID. Inicialmente, o sentimento de alívio e felicidade se instaurou por conta da bolsa, um fator que foi reconhecido por André (2018) em sua pesquisa com participantes dos 
programas de iniciação à docência. Contudo, apesar de cruzar minha vida apenas naquele ano, o caminho desta sigla de cinco letras não iniciou em 2018.

Em 2007, no mesmo momento em que eu estava na $3^{\text {a }}$ série do Ensino Fundamental I, o Programa Institucional de Bolsas de Iniciação à Docência (PIBID) surgia através do Plano de Desenvolvimento da Educação, compondo uma ação da Política Nacional de Formação de Professores do Ministério da Educação. Sob a responsabilidade da Coordenação de Aperfeiçoamento de Pessoal de Nível Superior (CAPES), o programa "visa proporcionar aos discentes na primeira metade do curso de licenciatura uma aproximação prática com o cotidiano das escolas públicas de educação básica e com o contexto em que elas estão inseridas” (CAPES, 2008).

Em seu primeiro Edital, no ano de 2007, para o processo de aprovação do subprojeto era necessário percorrer duas etapas: pré-qualificação e avaliação de mérito. A primeira, realizada pela CAPES, consistia em analisar se os subprojetos correspondiam aos pré-requisitos obrigatórios. Já a segunda, reforçava a prioridade de cursos de licenciaturas de física, química, biologia, matemática, ciências, letras e educação musical e artística em determinados segmentos de ensino da educação básica, examinada pela comissão organizadora do PIBID (CAPES, 2007).

Após três editais, no ano de 2011, o curso de licenciatura em Educação Física foi incluído na listagem de áreas apoiadas pelo PIBID (CAPES, 2011). Neste edital, no contexto da UFRJ, surge o subprojeto "Conhecimento, Educação Física e Autonomia”, que se desenvolveu com a atuação de 10 bolsistas licenciandos, 2 professores supervisores e 3 coordenadores. As ações articuladas foram desenvolvidas em parceria com 2 escolas estaduais. Entre os 10 bolsistas licenciandos, o meu futuro professor-supervisor estava ali construindo sua formação profissional, ainda como um licenciando de terceiro período.

Sete anos depois, finalmente eu e o "Subprojeto de Educação Física UFRJ: Cultura Corporal, Autonomia e Conhecimento" nos encontramos, no curso de Licenciatura em Educação Física da UFRJ, iniciando as ações em Agosto de 2018 e encerrando em Dezembro 2019. Contando com a participação de 24 bolsistas licenciandos, 6 licenciandos voluntários, 5 professores supervisores da educação 
básica e 1 coordenador, além de 3 escolas estaduais, 1 escola municipal e 2 federais do estado do Rio de Janeiro.

Desta forma, o subprojeto se desenvolveu assumindo o compromisso com a formação de professores incorporada à realidade profissional (ZEICHNER, 2010) e com debates e reflexões acerca da cultura corporal (jogos, esportes, ginásticas, danças e lutas), conteúdo a ser tematizado na Educação Física Escolar (SOARES et al, 2012). Assim, o subprojeto se configurou através de suas atuações no ambiente escolar e na universidade promovendo a construção de um " terceiro espaço" (ZEICHNER, 2010, p. 486), espaço de encontro entre a escola e a universidade superando a dualidade entre o espaço acadêmico e a prática profissional. Sendo assim, suas ações na escola foram: a Construção de Sequências Pedagógicas, a Foto Comentada, o Cine Cultura Corporal, a Jornada de Educação Física na escola e o Diário de Campo.

A Construção de Sequências Pedagógicas é um espaço que busca tematizar os componentes da cultura corporal, sendo organizado em três etapas (imersão, tematização e problematização) a fim de garantir a autonomia do estudante do ensino médio e seu reconhecimento enquanto sujeito reprodutor e produtor de cultura. A partir destas práticas pedagógicas da ação anterior, a Foto Comentada se materializa no registro de momentos que suscitam atravessamentos e apontamentos no ambiente educacional, seguido de uma reflexão crítica dos licenciandos sobre a mesma, visando alcançar públicos diversos para que se reconheçam protagonistas do processo das aulas de Educação Física.

O Cine Cultura Corporal é uma oportunidade que a comunidade escolar possui para assistir, refletir e debater as mídias audiovisuais que atravessam as práticas pedagógicas a respeito dos conteúdos. Como evento culminante das sequências pedagógicas, temos a Jornada de Educação Física na escola, que reúne a produção dos estudantes da educação básica em forma de trabalho, assegurando o estímulo à construção de novos conhecimentos. Por fim, há também o Diário de Campo concretizado por um pequeno caderno recebido no início do subprojeto, com o objetivo de acumular registros reflexivos pessoais por meio da escrita. Além disso, tal dispositivo tem sido objeto de reflexão de alguns companheiros e companheiras 
de PIBID, desdobrando em alguns trabalhos e textos sobre o seu papel em nossas trajetórias, como de Freire et al (2019).

As ações que vivi não se concentram apenas no quadrante escolar, mas fruíram para outros espaços, com destaque para os espaços universitários. Desse modo, na universidade acontecem: as Reuniões de coordenação, o Na Roda: Educação Física em debate, os Seminários identidade e profissão docente e o Encontro de Lá Pra Cá. A primeira consiste em encontros semanais com o objetivo de discutir e refletir com todos os membros do subprojeto (coordenador, professores-supervisores e licenciandos) sobre as atuações individuais, tornando-as também construções coletivas. Já a segunda, o Na Roda, é um evento aberto ao público que acontece mensalmente, oportunizando a ampliação de discussões sobre as abordagens pedagógicas da educação física escolar.

Os Seminários Identidade e Profissão docente que, assim como o Na Roda: Educação Física em debate, são eventos abertos ao público com o objetivo de refletir e discutir temas que transpassam a profissão docente e o meio educacional. Com o intuito de discorrer sobre políticas públicas e sociais que permeiam a sociedade, o evento conta com as parcerias de pesquisadores, professores e estudantes da rede básica de ensino para compor os debates. Já o Encontro De Lá Pra Cá é o momento em que os alunos do ensino médio vão até a universidade para participar das oficinas produzidas por licenciandos inscritos em disciplinas da graduação. $\mathrm{O}$ encontro possibilita a aproximação de professores em formação com estudantes do ensino básico, proporcionando marcas identitárias enquanto docente.

Quadro 1: As ações do subprojeto de Educação Física UFRJ

\begin{tabular}{|l|l|}
\hline \multicolumn{1}{|c|}{ Ações na escola } & \multicolumn{1}{c|}{ Ações na universidade } \\
\hline Construção de Sequências Pedagógicas & Reuniões de coordenação \\
\hline Cine Cultura Corporal & Na Roda: Educação física escolar em debate \\
\hline Foto Comentada & Seminários de Identidade e Profissão docente \\
\hline Diário de Campo & Encontro De Lá Pra Cá \\
\hline Jornada de Educação Física na escola & \\
\hline
\end{tabular}

Fonte: Martins et al, 2019. 
Sob este prisma, os meus $3^{\circ}, 4^{\circ}$ e $5^{\circ}$ períodos na graduação se desenvolveram enquanto bolsista do subprojeto supracitado, vivendo a interlocução direta com dois professores supervisores em instituições diferentes, o Colégio Estadual no ensino noturno, localizado no bairro Freguesia da cidade do Rio de Janeiro, e o Instituto Federal no ensino integrado (ensino médio + técnico), situado no bairro Vila Sarapuí do município de Duque de Caxias. Assim, o PIBID foi um espaço caracterizado pelo diálogo em que as ações localizadas no ambiente escolar e universitário ultrapassaram os espaços físicos, proporcionando uma formação de professores caracterizada pelo cruzamento das esferas formativas.

\section{Notas de uma formação contra hegemônica}

O campo educacional tem sido alvo de interesse dos grandes organismos multilaterais, como o Banco Mundial e a Organização para Cooperação e Desenvolvimento Econômico (OCDE), munidos com a justificativa de que a educação é o fator diferencial para o crescimento econômico do país. Desse modo, Saul e Saul (2016) tem apontado a necessidade desses grupos conservadores em apoiar moldes de formação docente que ocupam posição hegemônica, destacado por Diniz-Pereira (2011) como modelo da racionalidade técnica. Por outro lado, o autor sublinha em posição contra hegemônica estão os modelos da racionalidade prática e crítica.

O modelo da racionalidade técnica surge a partir da superioridade dos conhecimentos científicos distanciando-se da atuação profissional. Com base nos "problemas" encontrados durante a prática, os pesquisadores desenvolvem "técnicas" para que os profissionais da educação possam aplicá-las no exercício da profissão a fim de solucioná-los. Sob outra perspectiva, o modelo da racionalidade prática brota com a necessidade de superar a ideia de que os conhecimentos dosas professoresłas são como um kit de ferramentas para atingir a aprendizagem dosas estudantes. Partindo dessa concepção, a reflexão-na-ação é o ponto central da formação, uma vez que há o entendimento de que a realidade do trabalho docente é 
espontânea e por isso, não existe um método generalizado para lidar com as questões que permeiam as aulas.

E por fim, o modelo da racionalidade crítica aproxima-se da concepção proposta por Paulo Freire de que a visão política dóa professor/a permeia a sua prática pedagógica ao levantar de problemas, promovendo um espaço dialógico crítico. A partir disso, o autor destaca que neste modelo surge a identificação de professores-pesquisadores, ultrapassando a divisão de trabalho entre pesquisadoresas e professoresas reforçada na racionalidade técnica. Com isso, ele complementa que

Tendo dito isso, busco através do meu Diário de Campo recebido na quartauma comunidade de professores-pesquisadores, com estudantes como coinvestigadores, estabelece um processo democrático e centrado no aluno por meio do qual o currículo é construído "de baixo para cima" ao invés de ser construído "de cima para baixo". (DINIZ-PEREIRA, 2011, p. 27)

feira, dia 08 de Agosto de 2018, durante a primeira reunião de coordenação, entender qual ou quais modelos de formação surgem dos meus escritos. Lembro que algumas pessoas receberam um caderno na mistura de tons azul e verde, outros na mistura de tons de amarelo e vermelho, assim como o meu. Na capa do caderno tinha uma pequena etiqueta retangular com a arte do subprojeto centralizada na parte superior e, logo abaixo, outro retângulo com a palavra professora centralizada em cima do meu nome. Ao receber o caderno com esta etiqueta identifiquei que, no $3^{\circ}$ período da graduação de Licenciatura em Educação Física, já me reconhecia como professora.

Nesse sentido, considero que esse instrumento representou um impacto significativo para a minha formação, por isso decido neste estudo revisitar minhas reflexões, buscando conexões com os conceitos de práxis, dialogicidade e quefazer, propostos por Freire (2019). Sendo assim, compreendendo que práxis "é reflexão e ação dos homens sobre o mundo para transformá-lo" (FREIRE, 2019, p. 52), isto é, tornar a reflexão materializada na prática, buscando a promoção de transformação social. Por meio da práxis conseguimos alcançar nossa inserção crítica e coloca-la em ação, visando superar a contradição opressor-oprimido.

Fundamental para a educação como prática de liberdade, a dialogicidade é efetivada através do diálogo, compreendido como o "encontro dos homens, 
mediatizados pelo mundo, para pronunciá-lo, não se esgotando, portanto, na relação eu-tu" (FREIRE, 2019, p. 109. Desse modo, o diálogo é primordial para a efetivação da práxis, já que através da palavra, que não pode ser qualquer palavra, mas sim a palavra autêntica, por consequência do diálogo, as pessoas se reúnem a fim de denunciar o mundo e alcançar uma convergência de ação com o objetivo de transformar o mundo. Sendo assim, a dialogicidade não pode se dar por uma simples troca, mas de uma união e organização para atingir a liberdade que nos é negada devido a intensa desumanização prescrita.

Por fim, outro conceito abordado aqui será o quefazer que se constitui como "teoria e prática. É reflexão e ação" (FREIRE, 2019, p. 168), ou seja, significa a busca de um conteúdo para materializá-lo em prática. Portanto, quefazer se configura na práxis, na transformação do mundo, na dialogicidade de forma que não há possibilidade de se ter práxis sem o quefazer ou quefazer sem práxis, o mesmo acontece com a transformação do mundo e a dialogicidade.

Tendo explicitado os conceitos norteadores da pesquisa, as citações do Diário de Campo foram capazes de permitir a percepção de atravessamento entre os conceitos. O diálogo com os professores supervisores se mostrou relevante durante as Reuniões de coordenação, especificamente na segunda, onde a Proposta de Emenda à Constituição (PEC) $\mathrm{n}^{0} 55$ atravessou a pauta desencadeando temas que cercam a proposta. Desse maneira, destaco no diário que "O que mais me impactou foi a fala do prof Leandro quando disse que não existe Escola Sem Partido, por conta da ideologia”.

Do mesmo modo, a partir da citação "Gostei muito, porque foi em equipe e tinha a participação dos professores supervisores", ocorrido durante um dos encontros do Na Roda: Educação Física escolar em debate, observo que esses momentos de dialogicidade tornam a profissão docente e a luta pela revolução menos solitária. Além de oportunizar uma formação de professores atravessada pelas experiências dos professores da educação básica, uma vez que a potencialidade dessa comunicação proporciona um espaço de encontro práxis coletiva.

As práticas pedagógicas também provocaram contato com a práxis, por exemplo ao dissertar que "O pique capitão do mato foi um sucesso" em uma aula de 
capoeira, a atividade consistia em dividir a quadra em 3 espaços: liberdade, local onde o capitão do mato ficava para capturar os escravizados e, por último, o lugar dos estavam "presos". Desse modo, o objetivo consistia em apresentar como aconteciam as relações entre capitão do mato e os escravizados e, nessa proposta, considerei como "sucesso" o fato de que os/as estudantes que estavam no papel de escravizados conseguiram perceber que a partir da união entre eles tornaram-se capazes de passar pelo capitão do mato. Com isso, percebo que o diálogo com as pessoas envolvidas oportunizou que eu chegasse as reflexões sobre o trabalho docente naquele contexto, exteriorizada através da práxis.

E, após essa mesma aula ao destacar que "Nós (professores) deveríamos ter trazido mais músicas e atividades" e "Achei um pouco desorganizado" consigo perceber o quefazer, uma vez que o tema era Capoeira e a música é imprescindível para que a partir do diálogo a transformação do mundo se dê através da potência das letras e da musicalidade. Além disso, a práxis se fez presente ao assumir a falta de organização e músicas para que a prática se torne reflexão promovendo uma nova ação.

Outra questão relevante se deu ao mencionar durante a fase de imersão que "Não houve contextualização" da vivência que estava sendo feita, estabeleço um diálogo entre a teoria e a prática resgatando uma obra fundamental para a concepção crítica da Educação Física Escolar, intitulada como crítico-superadora ao procurar atender aos interesses da classe trabalhadora. Sendo assim, destacam Soares et al (2012) que:

É fundamental para essa perspectiva da prática pedagógica da Educação Física o desenvolvimento da noção de historicidade da cultura corporal. É preciso que o aluno entenda que o homem não nasceu pulando, saltando, arremessando, balançando, jogando etc. Todas essas atividades corporais foram construídas em determinadas épocas históricas, como respostas a determinados estímulos, desafios ou necessidades humanas (SOARES et al, 2012, p. 40).

Com isso, observo que os meus escritos têm apontado um alinhamento maior ao modelo da racionalidade crítica, a partir do reconhecimento de que a educação é "historicamente localizada" (DINIZ-PEREIRA, 2011, p. 25) se faz presente nos escritos. E, também, a preocupação em construir práticas pedagógicas contra 
hegemônicas na Educação Física Escolar, a fim de garantir que o trabalho pedagógico questione a realidade dos/as estudantes da educação básica oportunizando a práxis.

\section{Palavras finais}

A abordagem metodológica História de Vida tem sido explorada no campo de pesquisa de formação de professores. Sendo assim, tal perspectiva teórica foi fundamental na investigação, visto que através da narrativa pude refletir sobre as experiências enquanto as relatava. Dessa maneira, pude apreender de que forma a minha atuação no PIBID permitiu alcançar particularidades para encontrar pistas de uma formação de professores, sob a ótica contra hegemônica para além da racionalidade técnica e prática.

As ações desenvolvidas durante o "Subprojeto de Educação Física UFRJ: Cultura Corporal, Autonomia e Conhecimento" do PIBID no contexto da UFRJ me permitiram vivenciar a práxis durante os momentos de reflexão sobre as práticas pedagógicas construídas coletivamente. O quefazer enquanto busco relacionar as teorias discutidas, seja no Na Roda, seja em outros espaços formativos com as atuações no ambiente escolar. E, ainda, dialogicidade presente durante os diálogos entre licenciandos e licenciandos, professores supervisores e licenciandos, estudantes da educação básica e licenciandos, fomentando uma formação alinhada aos preceitos da concepção de educação libertadora, na busca por uma formação de professores contra hegemônica.

Em suma, a partir do entendimento de que estou imersa em múltiplos espaços formativos que proporcionam diversas vivências, almejo seguir a minha formação permanente, como nos remete Paulo Freire, aproximada à perspectiva contra hegemônica de formação, acreditando em quão preciosa essa particularidade tem sido para a minha trajetória.

\section{Referências}

ANDRÉ, Marli. Professores iniciantes: egressos de programas de iniciação à docência. Rev. Bras. Educ., Rio de Janeiro, v. 23, e230095, 2018. Disponível em <http://www.scielo.br/scielo.php?script=sci_arttext\&pid=S141324782018000100280\&lng=pt\&nrm=iso $>$. 
BAPTISTA, Maria Luiza. Emoção e subjetividade na paixão-pesquisa em comunicação. Revista Ciberlegenda, n. 4, p. 1-18, 2001.

BONDÍA, Jorge Larrosa. Notas sobre a experiência e o saber de experiência. Revista brasileira de educação, n. 19, p. 20-28, 2002.

CAPES. Edital MEC/CAPES/FNDE. In: Editais e Seleções. 2007. Disponível em: <https://uab.capes.gov.br/educacao-basica/capespibid/editais-e-selecoes>

PIBID. In: Pibid - Programa Institucional de Bolsa de Iniciação à Docência. 2008. Disponível em: <https://uab.capes.gov.br/educacaobasica/capespibid/pibid>

. Edital CAPES n ${ }^{0}$ 7/2018. In: Editais e Seleções. 2011. Disponível em: <https://uab.capes.gov.br/educacao-basica/capespibid/editais-e-selecoes>

DE SOUZA, Elizeu Clementino. (Auto) biografia, histórias de vida e práticas de formação. In: Nascimento AD; Hetkowski TM.(org.). Memórias e formação de professores. Salvador: EDUFBA; 2007. p. 59-74.

DINIZ-PEREIRA, Júlio Emílio. Capítulo 1: A pesquisa dos educadores como estratégia para construção de modelos críticos de formação docente. In: DINIZPEREIRA, Júlio Emílio; ZEICHNER, Kenneth M.(org.). A pesquisa na formação e no trabalho docente. Belo Horizonte: Autêntica Editora, $2^{\mathrm{a}}$ Ed., 2011, p.11-37.

FIGUEIREDO, Ângela. Fora do jogo: experiência dos negros na classe média brasileira.

Cadernos Pagu, n. 23, p.199-228, jul./dez. 2004.

FREIRE, Paulo. Pedagogia do Oprimido. Rio de Janeiro/São Paulo: Paz \& Terra, $71^{\text {a }}$ Ed., 2019

FREIRE, Carina; DE SOUZA, Beatriz; GATTO, Mariana; SARTI, Renato.O INÍCIO DA CARREIRA DOCENTE: O DIÁRIO DE CAMPO COMO DISPOSITIVO DE (IN)FORMAÇÃO PEDAGÓGICA. In: Anais do XXI Congresso Brasileiro de Ciências do Esporte e do VIII Congresso Internacional de Ciências do Esporte. Natal (RN): UFRN, 2019, p.1942.

INEP. Censo da educação superior 2017: divulgação dos principais resultados. Diretoria de Estatísticas Educacionais - Deed. Brasília: DF, 2018.

MARTINS, Roberto; FREIRE, Carina; SARTI, Renato. O ensino da Educação Física: Entre a cultura Corporal e a Produção Discente. In: Anais do XXI Congresso Brasileiro de Ciências do Esporte e do VIII Congresso Internacional de Ciências do Esporte. Natal (RN): UFRN, 2019, p.63. 
SAUL, Ana Maria; SAUL, Alexandre. Contribuições de Paulo Freire para a formação de educadores: fundamentos e práticas de um paradigma contrahegemônico. Educ. rev., Curitiba, n. 61, p. 19-36, Sept. 2016. Disponível em: $<$ http://www.scielo.br/scielo.php?script=sci arttext\&pid=S010440602016000300019\&lng=en\&nrm=iso $>$.

SOARES, C.; TAFFAREL, C.; ESCOBAR, M.; VARJAL, M..; CASTELLANI FILHO, L.; BRACHT, V. Metodologia do Ensino de Educação Física. São Paulo: Cortez, 2012.

SPINDOLA, Thelma; SANTOS, Rosângela. Trabalhando com a história de vida: percalços de uma pesquisa(dora?). Revista da Escola de Enfermagem da USP, v. 37, n. 2, p. 119-126, 2003.

ZEICHNER, Kenneth. Repensando as conexões entre a formação na universidade e as experiências de campo na formação de professores em faculdades e universidades. Educação, Santa Maria, v. 35, n. 3, p. 479-504, set./dez. 2010.

\section{Sobre os autores}

Beatriz Pereira: Graduanda em Licenciatura em Educação Física E-mail beapereira2011@hotmail.com ORCID https://orcid.org/0000-0002-0999-3200

Renato Sarti: Mestre e Doutorando em Ciências e Saúde pela Universidade Federal do Rio de Janeiro. Técnico em Assuntos Educacionais da Universidade Federal do Rio de Janeiro. Membro do Grupo de Estudos em Educação Física Escolar e Profissão Docente (GEEP/UFRJ) E-mail: renatosarti.eefd@gmail.com ORCID https://orcid.org/o000-0001-7553-4275

\section{Tramitação:}

Recebido em:26/o9/2021

Aprovado em:29/10/2021 